ISSN 0976 - 6995 (Print)

ISSN 0976 - 7002 (Online)

Volume 5, Issue 1, January - April (2014), pp. 12-22

(C) IAEME: https://iaeme.com/Home/journal/IJDMT

IJDMT

(C) I A E M E

https://doi.org/10.34218/IJDMT.5.1.2014.30320140501002

\title{
DESIGN OF THREE AXIS PICK AND PLACE MECHANISM FOR FRICTION WELDING MACHINE TO REDUCE THE TIME CYCLE AND TO INCREASE PRODUCTIVITY
}

\author{
CHAVAN D K ${ }^{1}$, PAWAR UDAYAN ${ }^{2}$, TAMBE NIHARIKA ${ }^{2}$, SANE ABHISHEK ${ }^{2}$ \\ ${ }^{1}$ Professor, Mechanical Engineering, MMCOE, Pune, Maharashtra, India \\ ${ }^{2}$ Graduate Engineering Students, MMCOE, Pune, Maharashtra, India
}

\begin{abstract}
This study aimed to create a proto-type robotic pick and place system that utilizes pneumatic components to drive an arm, an air compressor as a source of power, sensors technology as a feedback device, and a programmable logic controller. Robotic pick and place a system consists of a loading station, testing station, processing station, and sorting station. The process involves the pick and place operation for the friction welding machine, for loading and unloading operation of raw material. An optimum assembly design is then achieved with workable sub designs of the manipulator components. As a result, the proposed approach for manipulator design yields substantially less number of iterations, automatic propagation of design changes and great saving of design efforts. Further with best machining process and cheapest material, catering the strength and machining requirements suitable materials are selected to fulfil the objective.
\end{abstract}

Keywords: Pick and Place, Friction Welding, Pneumatics, End Effector, Electro Mechanical etc.

\section{INTRODUCTION}

Industrial automation has offered higher levels of productivity, efficiency, and quality as well as reduction to cost on the industry. In most Industries, the path towards increased productivity is through increased automation process and control. Automating using robot 
International Journal of Design and Manufacturing Technology (IJDMT), ISSN 0976 - 6995(Print), ISSN 0976 - 7002(Online) Volume 5, Issue 1, January - April (2014), pp. 12-22 @ IAEME

systems will increase productivity, efficiency and quality control. During operation, robots can be controlled to accommodate more work, and even operate beyond working hours.

In material handling and assembly there are many ways to move an item from one location to another. When the part orientation or alignment needs to be changed, a pick-and-place system is often used. The most common pick-and-place systems employ either pneumatics or electromechanical systems, with hybrid electric-pneumatic systems also an option in some applications. The amount of movement that must be performed, the required accuracy of the placement, the weight of the objects to be lifted, the shape of the parts, the distance they must travel, and other such considerations will determine the system best suited for the application.

\section{OBJECTIVES OF THE STUDY}

This paper aims to attain the following objectives:

- Design of three axis pick and place mechanism for friction welding machine to reduce time cycle and increase productivity.

- To build a proto-type robotic arm pick and place system;

- To verify the relationship between Electro-Pneumatic components and PLC; and

- To achieve a program with the system's proper motion sequence using a Programmable Logic Controller (PLC).

\section{WHY PNEUMATICS}

Pneumatics has long since played an important role as a technology in the performance of mechanical work. It is also used in the development of automation solutions. functions:

In the majority of applications compressed air is used for one or more of the following

- To determine the status of processes (sensors)

- Information processing (processors)

- Switching of actuators by means of final control elements

- Carrying out work (actuators)

To be able to control machinery and installations necessitates the construction of generally complex logic interconnections of status switching conditions. This occurs as a result of interaction sensors, processes, control elements and actuators in pneumatic or partly pneumatic systems.

The technological progress made in material, design and production processes has further improved the quality and diversity of pneumatic components and thereby contributed to their widely spread use in automation.

Pneumatic components can perform the following types of motion:

- Linear

- Swivel

- Rotary 
International Journal of Design and Manufacturing Technology (IJDMT), ISSN 0976 - 6995(Print), ISSN 0976 - 7002(Online) Volume 5, Issue 1, January - April (2014), pp. 12-22 @ IAEME

\section{MANIPULATOR DESIGN}

A manipulator is generally mounted on a track or suspended from a track that is capable of reaching various distances and locations. It is used to move materials, tools and objects without direct human contact. It consist of two sections namely the body or arm and the wrist assembly.

\section{DESIGN OF BODY}

The body is used to position the object in the robot's work envelop. And thus by employing the concept of value engineering proper design can help reduce the weight of the body and also the amount of materials used. Generally to optimize both material cost and the manufacturing cost the arm is made up of different components and then is assembled together, thus saving the material and cost.

\section{DESIGN OF WRIST ASSEMBLY}

It is used for the orientation of the object in the work envelop. The end effector is attached to the wrist assembly. Wrist assembly has three degrees of freedom pitch, roll and yaw. However for simple pick and place application keeping in mind the complexity of manufacturing of the wrist assembly the end effector can be attached to the arm directly using hinged joints. Pneumatic cylinder is used for controlling the end effector. Thus contributes significantly in reducing the cost of the robot.

\section{DESIGN OF END EFFECTOR}

The arm is responsible only for positioning the object and the end effector interacts with the object. The hand of the robot is considered as the end effector. The various end effectors are grippers, sprayers, grinders, welders and vacuum. Here we choose to use either a gripper or a vacuum. A gripper used for lifting and placing objects is simple to design and manufacture. A vacuum can use the pneumatic power and thus reduce the running cost and also perform complex tasks.

\section{ROTATION OF THE ROBOT}

For the robot to reach different locations and perform the tasks it has to rotate around its own axis. Thus depending up on the requirement either a stepper motor or a simple pneumatic cylinder can be used. A stepper motor needs electronic circuits for control and an additional bearing support for 360 degree rotation. Here only one bearing to support the rotation is required. Thus significantly reducing the cost of the robot.

\section{PNEUMATIC CIRCUIT}

A pneumatic logic system is generally used to control the industrial robots. Pneumatic circuits are accurately and precisely designed and implemented. Sequential circuits are designed so that each cylinder is actuated at proper sequence and are also kept active for the desired period of time. This the only challenge in a low cost robotic arm is designing of the pneumatic circuit. 
International Journal of Design and Manufacturing Technology (IJDMT), ISSN 0976 - 6995(Print), ISSN 0976 - 7002(Online) Volume 5, Issue 1, January - April (2014), pp. 12-22 @ IAEME

\section{MATERIAL SELECTION}

Material selection is one of the most important factors in reducing the cost of the robot. Materials are selected in such a way that there is no compromise in optimum design.

\section{DESIGN}

\subsection{CALCULATIONS FOR END EFFECTOR}

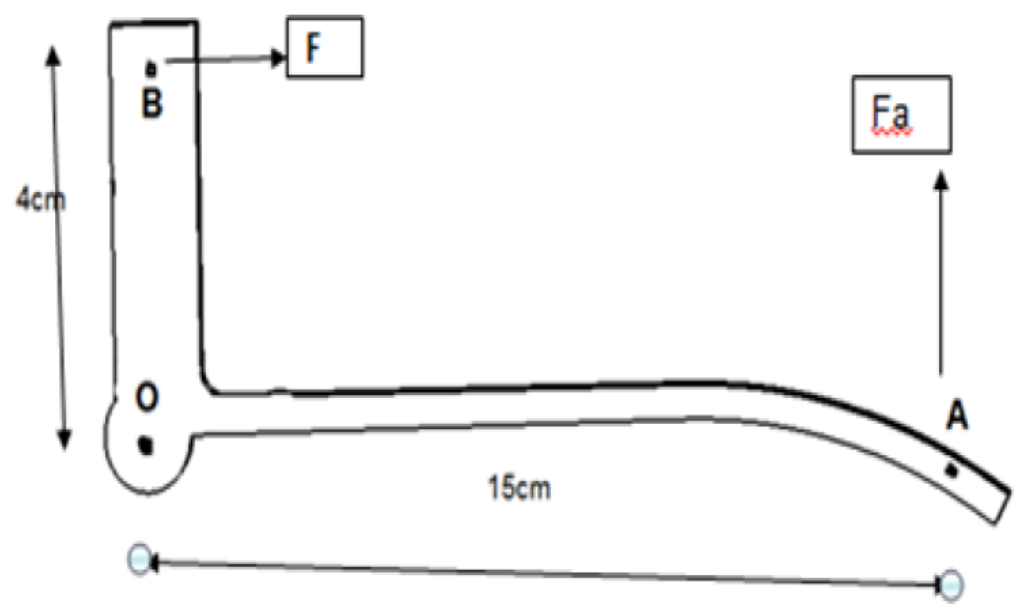

Fig 1: Gripper Design

Force $(\mathrm{Fa})$ required for holding the work piece is $30 \mathrm{~N}$

$\mathrm{Fa}=10 \mathrm{~N}$

From above figure: Take moment at point $\mathrm{O}$,

Let force at point $\mathrm{B}$ be $\mathrm{F}$ and is equal to the force applied by the cylinder. Fa is the force required to hold the object

$\mathrm{Fa} \times 15=\mathrm{F} \times 4$

$\mathrm{F}=10 \times(15 / 4)$

$\mathrm{F}=37.5 \mathrm{~N}$

Thus $37.5 \mathrm{~N}$ of force should be supplied by the pneumatic

\subsection{SELECTION OF BODY CYLINDER}

$\mathrm{D}=$ Diameter of Piston

L=Length of Stroke

1.FORCE CALCULATION FOR DOUBLE ACTING CYLINDER

$\mathrm{F}_{\mathrm{TH}}=\mathrm{P} \times \mathrm{A}$

$\mathrm{P}=$ OPERATING PRESSURE $(\mathrm{Pa})=5 \times 10 \mathrm{~N} / \mathrm{m}^{2}$

$\mathrm{A}=\mathrm{USEFUL} \mathrm{PISTON} \mathrm{AREA}\left(\mathrm{m}^{2}\right)$

NOW,

$\mathrm{A}=\mathrm{D} \times 1$ (dia $\times$ stroke $)$

$\mathrm{F}_{\mathrm{TH}}=\mathrm{P} \times \mathrm{A}$

Frictional resistance $=10 \% \times \mathrm{F}_{\mathrm{TH}}$

FORWARD STROKE

$\mathrm{F}_{\text {eff }}=(\mathrm{A} \times \mathrm{P})-\mathrm{F}_{\mathrm{R}}$ 
International Journal of Design and Manufacturing Technology (IJDMT), ISSN 0976 - 6995(Print), ISSN 0976 - 7002(Online) Volume 5, Issue 1, January - April (2014), pp. 12-22 @ IAEME

$\mathrm{A}=\pi / 4 \times \mathrm{d}^{2}$

Return stroke

$\mathrm{F}_{\text {eff }}=(\mathrm{A} \times \mathrm{P})-\mathrm{F}_{\mathrm{R}}$

$\mathrm{A}=$ useful piston area for return stroke

$\mathrm{A}=\pi / 4 \times\left(\mathrm{D}^{2}-\mathrm{d}^{2}\right)$

By following above procedure any cylinder dimensions and forces can calculated..

- Example:

FESTO DSNU-25-25-PPV-A

$\mathrm{D}=25 \quad \mathrm{~L}=25$

1.FORCE CALCULATION FOR DOUBLE ACTING CYLINDER

$\mathrm{F}_{\mathrm{TH}}=\mathrm{P} \times \mathrm{A}$

$\mathrm{P}=$ OPERATING PRESSURE $(\mathrm{Pa})=5 \times 10 \mathrm{~N} / \mathrm{m}^{2}$

$\mathrm{A}=\mathrm{USEFUL} \mathrm{PISTON} \mathrm{AREA}\left(\mathrm{m}^{2}\right)$

NOW,

$\mathrm{A}=\mathrm{D} \times 1$ (dia $\times$ stroke $)$

$=25 \times 10^{-3} \times 25 \times 10^{-3}$

$\mathrm{A}=6.25 \times 10^{-4} \mathrm{~m}^{2}$

$\mathrm{F}_{\mathrm{TH}}=\mathrm{P} \times \mathrm{A}$

$\mathrm{F}_{\mathrm{TH}}=5 \times 10^{5} \times 6.25 \times 10^{-4}$

$\mathrm{F}_{\mathrm{TH}}=312.5 \mathrm{~N}$

Frictional resistance $=10 \% \times \mathrm{F}_{\mathrm{TH}}$

$\mathrm{F}_{\mathrm{R}}=31.25 \mathrm{~N}$

FORWARD STROKE

$\mathrm{F}_{\mathrm{eff}}=(\mathrm{A} \times \mathrm{P})-\mathrm{F}_{\mathrm{R}}$

$\mathrm{A}=\pi / 4 \times \mathrm{d}^{2}$

$=\pi / 4 \times\left(25 \times 10^{-3}\right)^{2}$

$\mathrm{A}=4.90625 \times 10^{-4} \mathrm{~m}^{2}$

$\mathrm{F}_{\text {eff }}$ for forward stroke of cylinder

$\mathrm{F}_{\text {eff }}=\left(4.90625 \times 10^{-4} \times 5 \times 10^{5}\right)-31.25$

$\mathrm{F}_{\text {eff }}=214.06 \mathrm{~N}$

Return stroke

$\mathrm{F}_{\text {eff }}=(\mathrm{A} \times \mathrm{P})-\mathrm{F}_{\mathrm{R}}$

$\mathrm{A}=$ useful piston area for return stroke

$\mathrm{A}=\pi / 4 \times\left(\mathrm{D}^{2}-\mathrm{d}^{2}\right)$

$\mathrm{A}=\pi / 4 \times\left(\left(25 \times 10^{-3}\right)^{2}-\left(12 \times 10^{-3}\right)^{2}\right)$

$\mathrm{A}=1.32665 \times 10^{-4} \mathrm{~m}^{2}$

$F_{\text {eff }}=\left(1.5072 \times 10^{-4} \times 5 \times 10^{5}\right)-31.25$

$\mathrm{F}_{\text {eff }}=35.08 \mathrm{~N}$

\section{COMPONENTS OF PNEUMATIC SYSTEM}

\subsection{FRL (FILTER -REGULATOR-LUBRICATOR)}

The Filter-Regulator-Lubricator unit (FRL) is probably one of the most important but over looked components of a pneumatic distribution system. The FRL is energy saving device, lowered noise levels and increased tool/device/machine service life. 
International Journal of Design and Manufacturing Technology (IJDMT), ISSN 0976 - 6995(Print), ISSN 0976 - 7002(Online) Volume 5, Issue 1, January - April (2014), pp. 12-22 @ IAEME

\subsection{DIRECTIONAL CONTROL VALVES}

Directional control valves are devices involves:

- Opening the passage of air and directing it to a particular line or lines, cancelling air signals as required by blocking their passage and relieving the air to the atmosphere via an exhaust port.

- Its number of controlled connections or ways, the number of switching positions and the methods of actuation characterize the directional control valve.

\subsection{FLOW CONTROL VALVE}

A flow control valve has a spring-loaded disk, which allows a free flow in one direction and an adjustable or controlled flow in the opposite direction.

\subsection{PNEUMATIC ACTUATORS}

- Pneumatic cylinders are low pressure cylinder, they are either low or medium and a lighter in construction.

- Pneumatic cylinder construction makes extensive use of aluminium and other nonferrous alloy materials to reduce the weight and the corrosive effects of air and to improve heat transfer capabilities.

\subsection{PNEUMATIC CYLINDERS}

The various industrial applications for which air cylinders are used can be divided duty-wise into three groups: light duty, medium duty and heavy duty.

According to the principle of operation, air cylinders are classified as:

- Single acting cylinders

- Double acting cylinders

\section{VENTURI PRINCIPLE}

Compressed air at a given rate is accelerated through a nozzle of narrow cross-section. The air stream is then emitted into a wider receiver nozzle. If the cross-section is reduced, the pressure drops compared to the larger cross-section.

We know that,

1. Potential energy - depending on the absolute pressure

2. Kinetic pressure - depending on the flow velocity

Neglecting frictional losses we get,

P.E + K.E $=$ constant

This formula states that the total energy is constant everywhere in the pipe. Therefore, if the velocity of the flowing air is increased due to the narrowing of the pipe, the pressure drops. 
International Journal of Design and Manufacturing Technology (IJDMT), ISSN 0976 - 6995(Print), ISSN 0976 - 7002(Online) Volume 5, Issue 1, January - April (2014), pp. 12-22 @ IAEME

\section{TIMERS}

Stating the interval to be timed and the conditions or events that are to start and/or stop the timer specify a timer circuit.

\section{OPERATIONAL DIAGRAM}

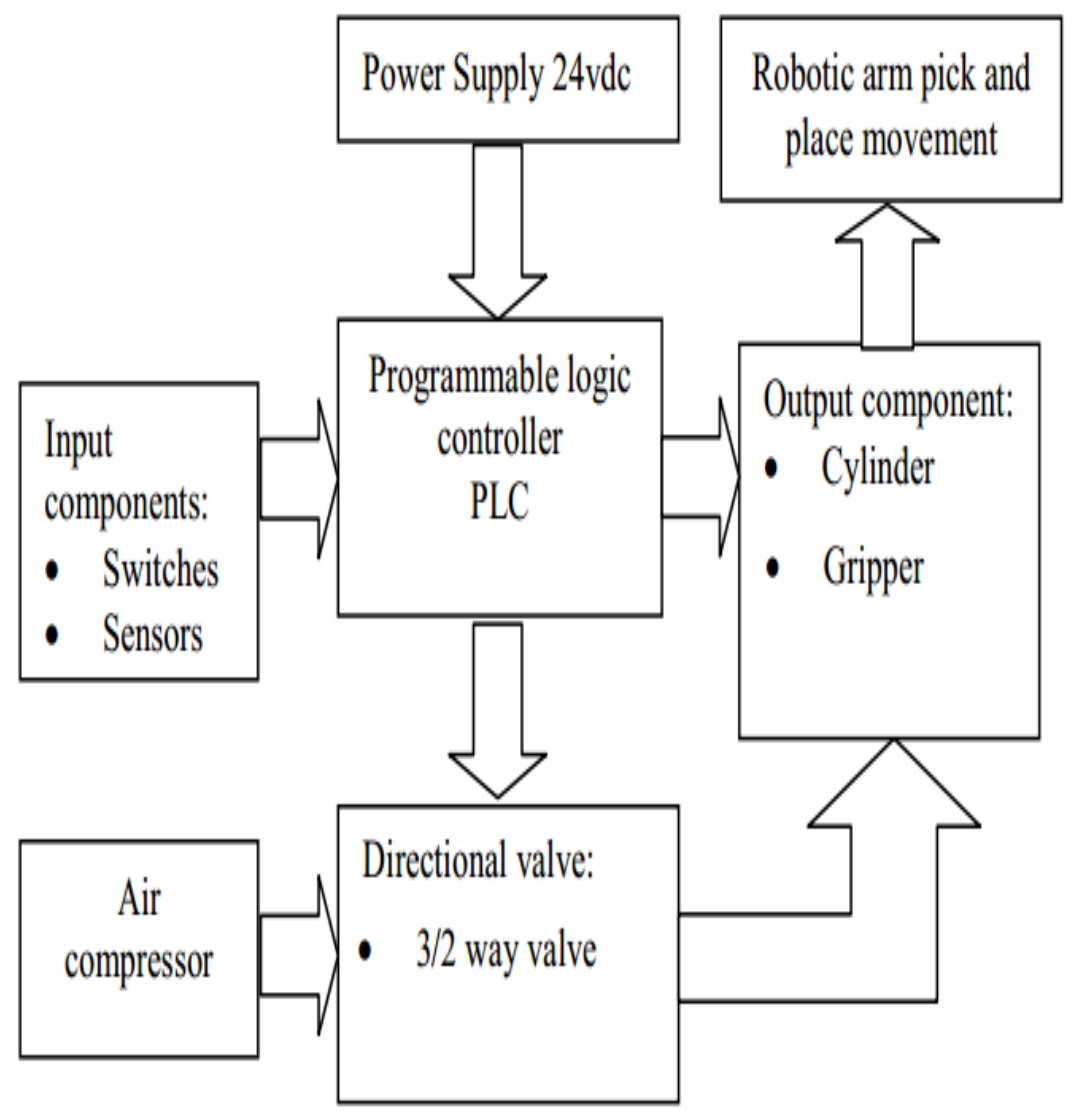

Fig 3: Flow Diagram of mechanism

The system is centrally controlled by a programmable logic controller, which every input and output data are fed in the PLC. The PLC processes information that happens in the input and output components of the robotic arm pick and place system. Input components are switches that include the start, stop, emergency stop button, and the inductive and capacitive sensors. The PLC is electrically generated by a voltage power supply of $24 \mathrm{Vdc}$. Robotic arm pick and place system movement is powered by a compressed air.

\section{CLOSED-LOOP CONTROL SYSTEM}

In a closed-loop controller or feedback controller, the output of the system is fed back through a sensor measurement to the reference value. The controller then takes the error between the reference and the output to change the inputs to the system under control. Since the input and the output components are directly connected to the controller or PLC, the feedback connection of the sensor from the output cannot be seen externally. It is usually found in the internal connection of the PLC. 
International Journal of Design and Manufacturing Technology (IJDMT), ISSN 0976 - 6995(Print), ISSN 0976 - 7002(Online) Volume 5, Issue 1, January - April (2014), pp. 12-22 @ IAEME

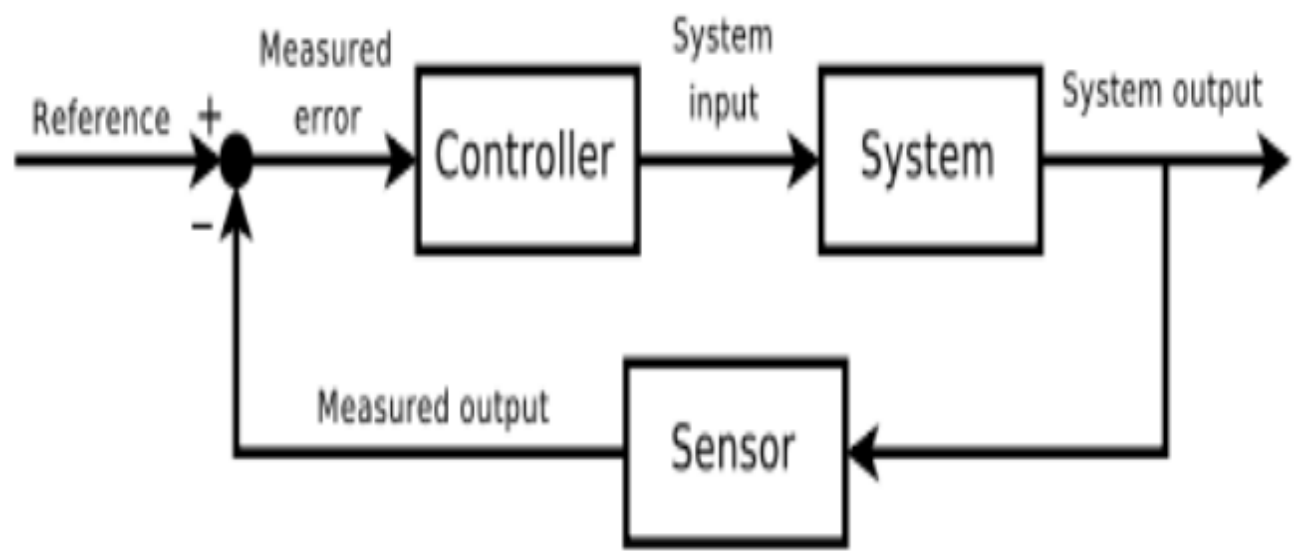

Fig 4: Closed-Loop Control System

\section{ROBOTIC ARM PICK AND PLACE SYSTEM}

The robotic arm pick and place system consists of a loading station, friction welding, bending test of weld and sorting station.

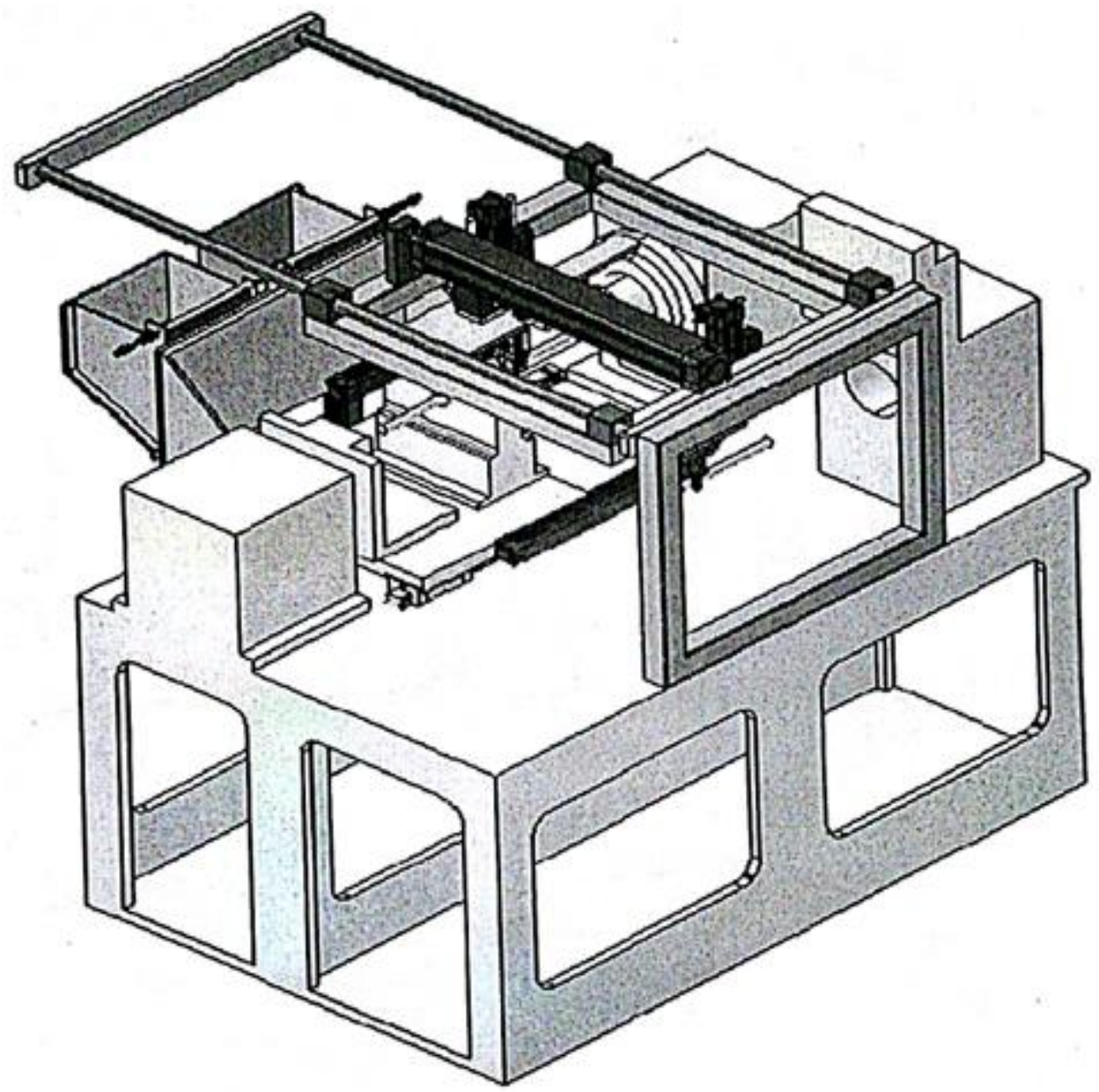

Fig 5: Robotic Arm Assembly 
International Journal of Design and Manufacturing Technology (IJDMT), ISSN 0976 - 6995(Print), ISSN 0976 - 7002(Online) Volume 5, Issue 1, January - April (2014), pp. 12-22 @ IAEME

\subsection{Loading Station(Hopper)}

In this station, metal materials which are to be friction weld are loaded manually. Only one material at a time comes in to the ' $\mathrm{V}$ ' slot from each hopper and then picked by the end effector and load in to the chuck and fixture.

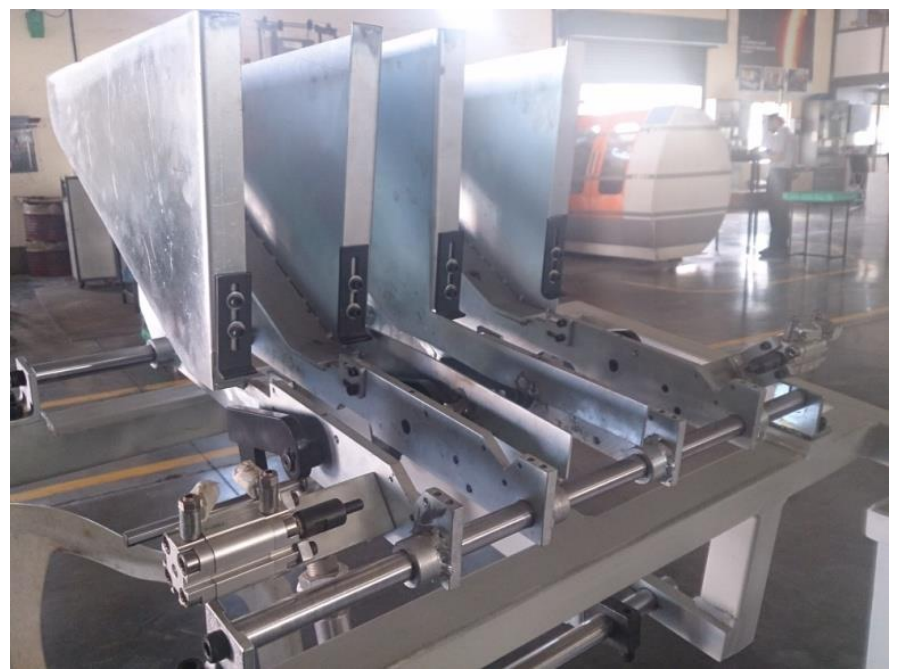

Fig 6: Hopper Assembly

\subsection{Friction Welding}

Friction welding process takes place to join two materials. Collar formed in friction welding process is removed by stamping process or turning process.

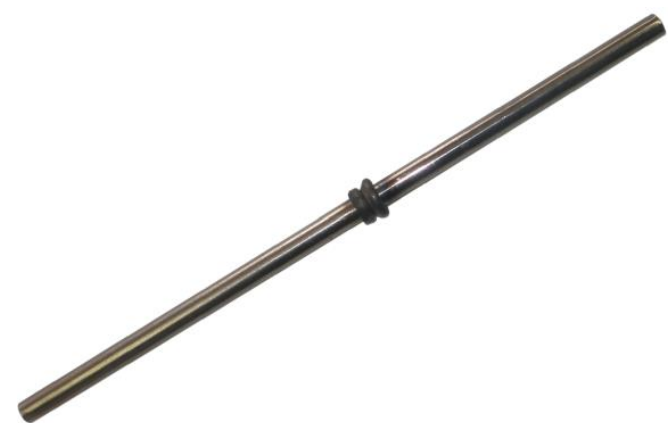

Fig 7: Friction Weld

\subsection{Bend Test}

To ensure the quality of weld bending test is performed.

\section{CONCLUSION}

The effective design and manufacturing of 3 degree of freedom pick and place robot has been performed. The operation of various arm linkages and the end effector has been extensively tested and the required corrective measures were taken. Hence the objective of designing and manufacturing of a pick and place robot at low cost was successful and can be implemented to replace the expensive electronic robots. It's been proved that running cost of the robot is also very less. This will help to cut down labour and improve profits at very low initial investment. 
International Journal of Design and Manufacturing Technology (IJDMT), ISSN 0976 - 6995(Print), ISSN 0976 - 7002(Online) Volume 5, Issue 1, January - April (2014), pp. 12-22 @ IAEME

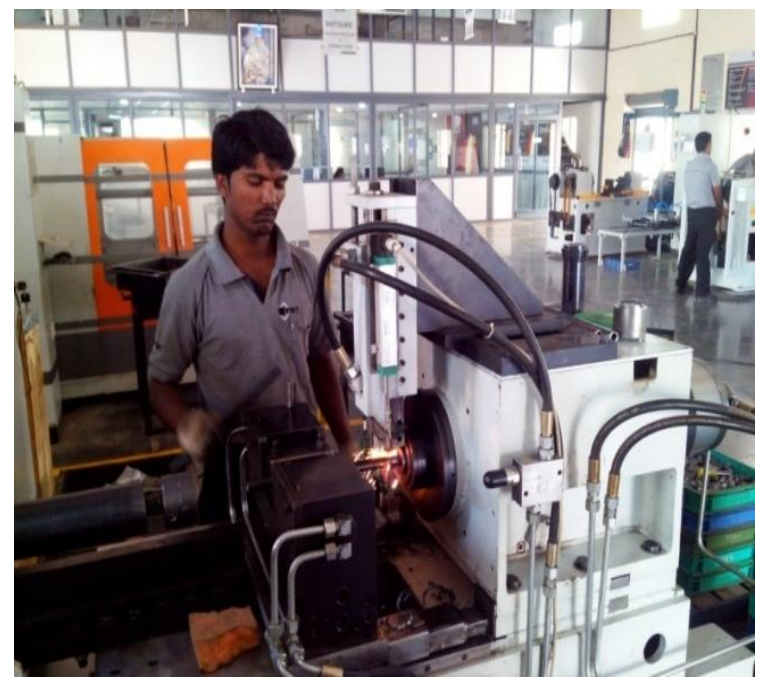

Fig 8: Friction Welding machine before Automation

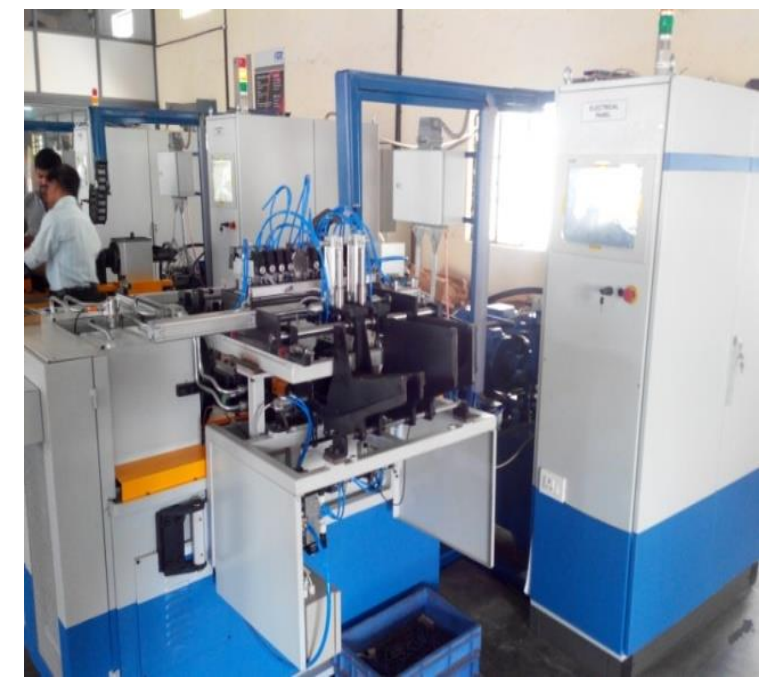

Fig 9: Friction Welding machine after Automation

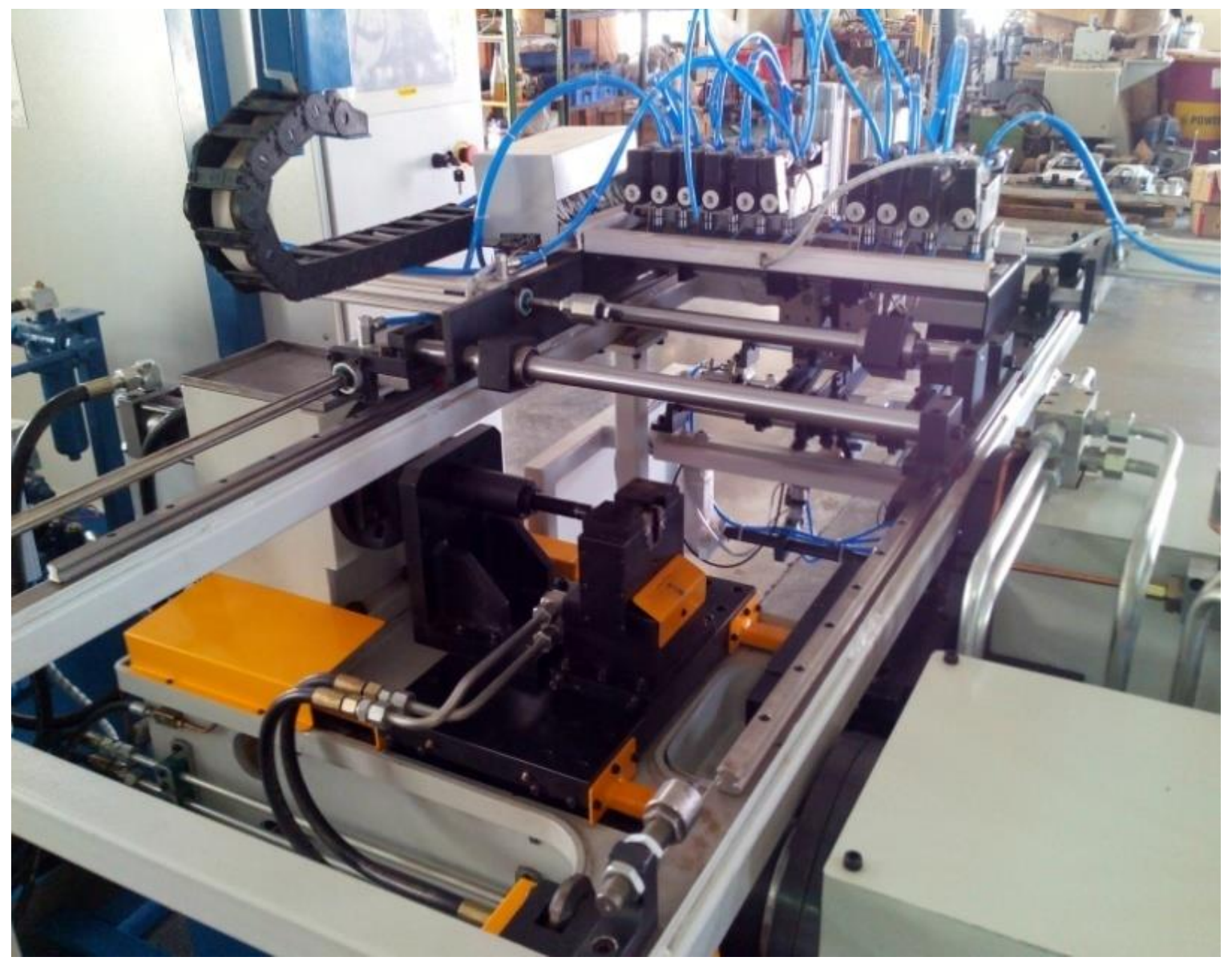

Fig 10: Robotic Arms on Slider Assembly 
International Journal of Design and Manufacturing Technology (IJDMT), ISSN 0976 - 6995(Print), ISSN 0976 - 7002(Online) Volume 5, Issue 1, January - April (2014), pp. 12-22 @ IAEME

\section{REFERENCES}

\section{A. BOOKS}

1. Fluid Power with Applications-Anthony Esposito

2. Introduction to Fluid Power - James Johnson

\section{B. INTERNET SOURCE}

1. http.//www.robotics.org

2. http.//www.nasa.gov

3. http.//www.space.gc.ca 